\section{Pacific Northwest}

National Laboratory

Operated by Battelle for the

U.S. Department of Energy

\title{
Infrared Imaging for the Detection of Radioactive Material in Various Storage Containers
}

\author{
T. J. Peters
}

May 2004

Prepared for the U.S. Department of Energy

under Contract DE-AC06-76RL01830 


\title{
DISCLAIMER
}

This report was prepared as an account of work sponsored by an agency of the United States Government. Neither the United States Government nor any agency thereof, nor Battelle Memorial Institute, nor any of their employees, makes any warranty, express or implied, or assumes any legal liability or responsibility for the accuracy, completeness, or usefulness of any information, apparatus, product, or process disclosed, or represents that its use would not infringe privately owned rights. Reference herein to any specific commercial product, process, or service by trade name, trademark, manufacturer, or otherwise does not necessarily constitute or imply its endorsement, recommendation, or favoring by the United States Government or any agency thereof, or Battelle Memorial Institute. The views and opinions of authors expressed herein do not necessarily state or reflect those of the United States Government or any agency thereof.

\author{
PACIFIC NORTHWEST NATIONAL LABORATORY \\ operated by \\ BATTELLE \\ for the \\ UNITED STATES DEPARTMENT OF ENERGY \\ under Contract DE-AC06-76RL01830
}

Printed in the United States of America

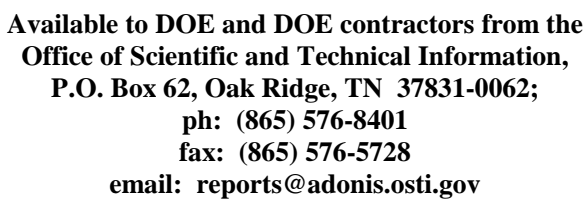

Available to the public from the National Technical Information Service, U.S. Department of Commerce, 5285 Port Royal Rd., Springfield, VA 22161 ph: (800) 553-6847 fax: $(703) 605-6900$

email: orders@ntis.fedworld.gov

online ordering: http://www.ntis.gov/ordering.htm 


\title{
Infrared Imaging for the Detection of Radioactive Material in Various Storage Containers
}

\author{
T. J. Peters
}

May 2004

Prepared for

the U.S. Department of Energy

under Contract DE-AC06-76RL01830

Pacific Northwest National Laboratory

Richland, Washington 99352 


\section{Summary}

Three separate tests were conducted in 2003 and 2004 at the Plutonium Finishing Plant (PFP) at the Hanford, Washington site to determine if infrared imaging can be used to detect the presence of radioactive material in various storage containers. The tests were conducted at the two most common infrared wavelength ranges used for nondestructive evaluations, 3-5 microns and 8-12 microns. The results of the tests indicate that infrared imaging can be used to detect the presence of stored radioactive materials. However, the temperature difference between the end plates and the ambient temperature is generally not large, about $1^{\circ} \mathrm{F}$. Some of the end plates were much hotter than others, probably due to the amount, type, and location of the material stored in them and any packing material also stored in the containers. Although there was consistency between the three tests, there were also some inconsistencies, probably due to reflections and emissivity differences in the surface of the end plates. There was excellent consistency between the random temperature measurements made with a contact thermocouple and the infrared image. In addition, testing with the radio-reflectors indicated that the presence of stored radioactive materials in the middle of the canister can be detected easier than at the end plate. It is recommended that infrared imaging continue to be explored as a possible method to determine the contents of the storage containers. The 64 rack-mounted Model 60 containers could be scanned from a distance in less than ten minutes, and this time could be decreased even further with a shorter focal length lens on the infrared cameras. This would greatly limit personnel exposure when taking inventory of the containers. 


\section{Contents}

Introduction 


\section{Figures}

1 Arrangement and Numbering of Model 60 Storage Canisters.................................................. 3

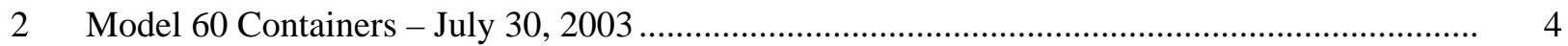

3 Model 60 Containers - December 30, 2003 ............................................................................ 5

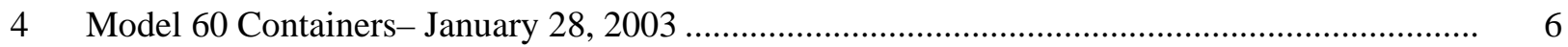

5 Close-Up of Some of the Model 60’s Containers................................................................

$6 \quad$ Enhanced Black and White Image with VideoTherm Camera ................................................. 8

$7 \quad$ Model 60 PseudoColored Image from VideoTherm............................................................. 9

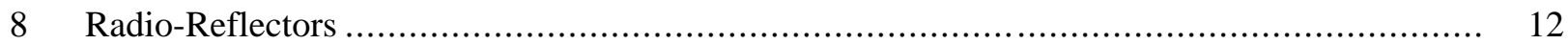

9 Infrared Image of Retro-Reflector Near Door Perpendicular to Other Tubes...................... 12

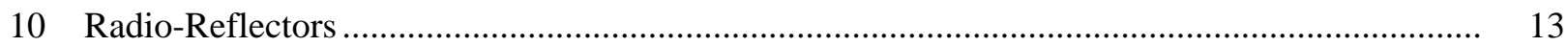

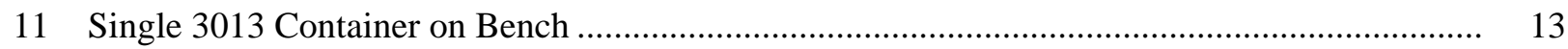

12 Infrared Images of 3013 Containers in Transport Wagon ................................................... 14

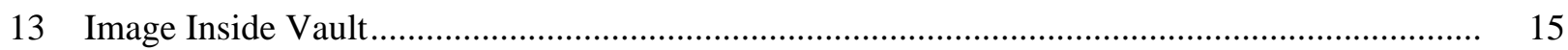

\section{Tables}

1 Comparison of Three Tests with the IRRIS Infrared Camera ................................................. 10

2 Comparison of Thermocouple Measurement to IR Image................................................... 10 


\section{Introduction}

Tests were conducted on July 30, 2003, December 30, 2003, and January 28, 2004, at the Plutonium Finishing Plant (PFP) at the Hanford, Washington site to determine if infrared imaging can be used to detect the presence of sources in:
a. Model 60 containers
b. radio-reflectors
c. 3013 Cans
d. storage vaults.

Most of these tests were done on the Model 60 containers with the IRRIS 256-ST infrared imager. The IRRIS 256-ST imager, manufactured by Cincinnati Electronics, operates in the 3-5 micron wavelength region. It is capable of resolving $0.05^{\circ} \mathrm{F}$, but is accurate to only $4^{\circ} \mathrm{F}$. In addition, testing in December 2003 was conducted with a VideoTherm Model 94 infrared imager, manufactured by ISI Group, Inc. This imager operates in the 8-12 micron wavelength region. Objects near room temperature, which is the temperature range of these storage containers, are generally viewed in the 8-12 micron wavelength region. One advantage of the VideoTherm is that it is a portable instrument designed for field work. However, the VideoTherm is an older imager and does not have the resolution $\left(1^{\circ} \mathrm{F}\right)$ that the IRRIS imager does. It is also an analog device compared to the IRRIS imager, which stores the images digitally, and gives more freedom for analyzing the images after recording. The other advantage of the VideoTherm is that it is a less expensive instrument. Although no longer manufactured, these instruments are still available through some dealers for about $\$ 7000$, compared to the $\$ 100,000$ for the new Cincinnati Electronics imager. A 25-mm focal length lens was used for both imagers.

\section{Model 60 Containers}

The rack-mounted containers in room 192A consisted of 10 columns and seven rows as shown in Figure 1. Because of the limited space and the field of view of the lens, a series of images was recorded of the end plates of the Model 60 containers mounted in the rack. These images were then normalized and pieced together to form a complete image of the containers on the rack.

\section{IRRIS 256-ST Imager}

The assembled image with the IRRIS 256-ST imager from the test in July 2003 is shown in Figure 2, and the assembled images of the Model 60 containers from the test in December 2003 are shown in Figure 3, and from the test in January 2004 in Figure 4.

A comparison of the images is shown in Table 1. The composite image taken each day was subjectively examined and the 'hot' end caps were noted. Of the 56 end caps examined (excluding the missing data, which occurred in the December test because the emphasis of this test was with the VideoTherm imager, so the test with the IRRIS 256-ST imager in December was performed quickly by hand scanning rather than setting it on a tripod, as was done for the other tests), 33 consistently indicated 
warmth (or lack of it) on all three tests, 5 end caps appeared warm in two of the three tests, and 18 end caps appeared warm in only one of the images. Most of the time that the end cap appeared warm in only one image occurred in the first test. The containers on the lower left side of the rack appeared warm during the first test, but did not appear warm in subsequent tests. The reason for this is not clearly understood except, when the test was done in July, it was warmer in the room, and the end cap may have been reflecting the heat from something else. All of the end caps on the lower left side of the rack are stainless steel, which could act as a reflector of infrared energy; whereas the end caps in the upper right of the rack are painted, and these consistently showed the same heat pattern in all three tests. If the containers on the left of the rack are ignored, then of the 47 containers that remain, 33 indicate warmth (or lack of it) in all three images, 5 indicated warmth in two of the three images, and 9 indicated warmth in only one image. If the first test is ignored completely, then 25 end caps indicated warmth between the two remaining tests, and 20 times there is a match between the two images.

During the January 2004 test series, a test was conducted to determine if greater accuracy could be obtained by looking at each end cap individually. The results are shown in Figure 5. Because some of these end caps are stainless steel, one had to be careful not to place the imager directly in front of the end cap being viewed, otherwise a reflection from the person taking the data, or the heat from the camera, would be seen. The results do not indicate a substantial difference between the data taken this way and the data taken at a distance. In addition, this method of testing was very time-consuming, taking over an hour to obtain images of the 19 end caps, whereas the images of the end caps of all 64 containers taken from a distance was obtained in about ten minutes. So testing these containers by examining individual end caps is not recommended.

\section{VideoTherm 94 Imager}

The enhanced black and white image of the Model 60 containers using the VideoTherm camera is shown in Figure 6, and the pseudo color image is shown in Figure 7. The warmer the end cap, the whiter is the end cap in the black and white image. The coloration in the color image is more complex due to the processing used to create this image, but essentially the warmer the end cap, the better it stands out from the background. As can be seen from these images, the resolution of the VideoTherm imager is much lower than with the IRRIS 256-ST imager. So although it is a less expensive camera and more portable, it is not recommended to be used for this application.

A contact thermocouple probe was used to measure the temperature of some of the containers, and the results are consistent with the infrared images taken on December 30, 2003. Table 2 summarizes these results, which indicate a good correlation between the infrared image and the measured temperature with a contact thermocouple. 


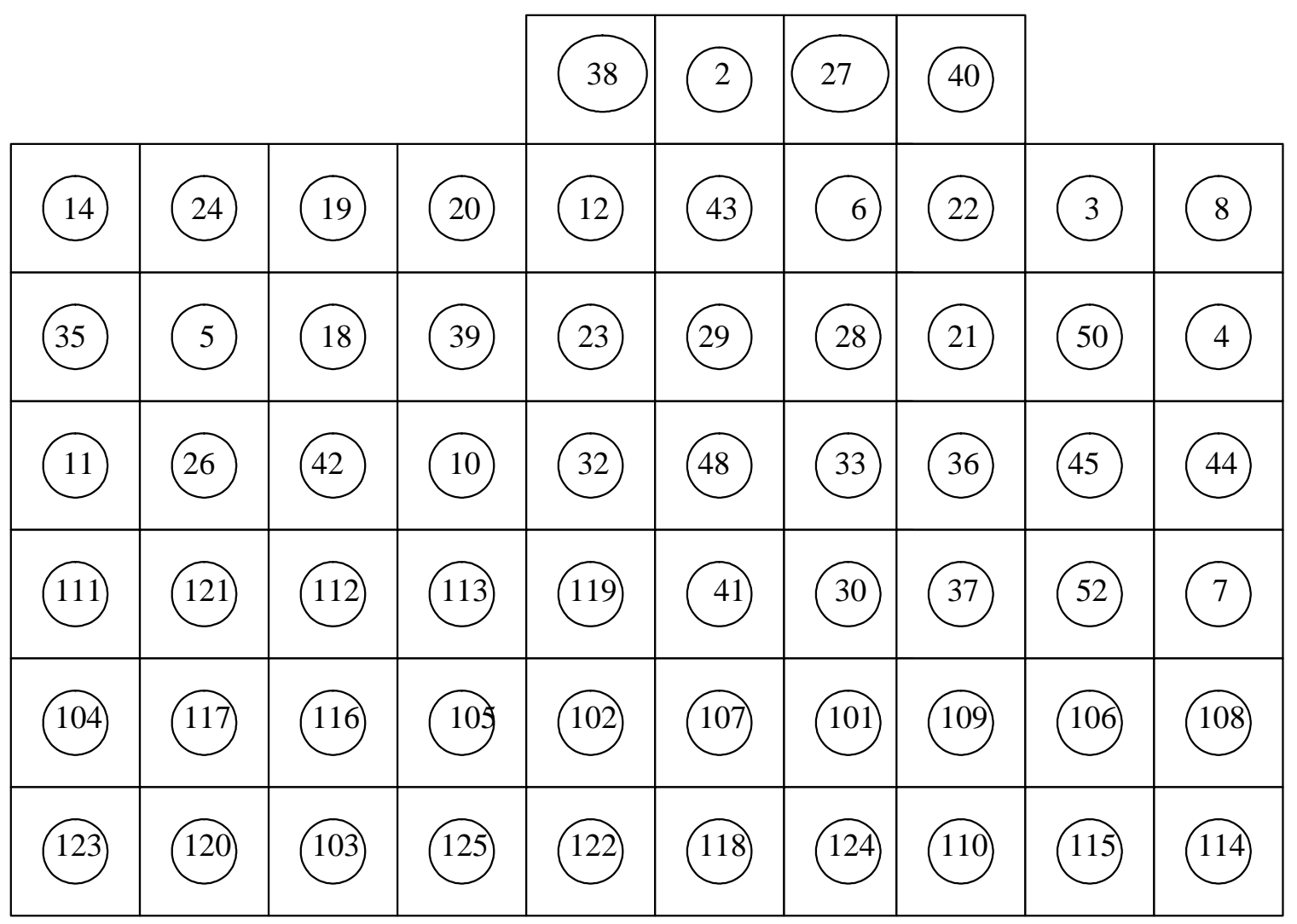

Figure 1. Arrangement and Numbering of Model 60 Storage Canisters 


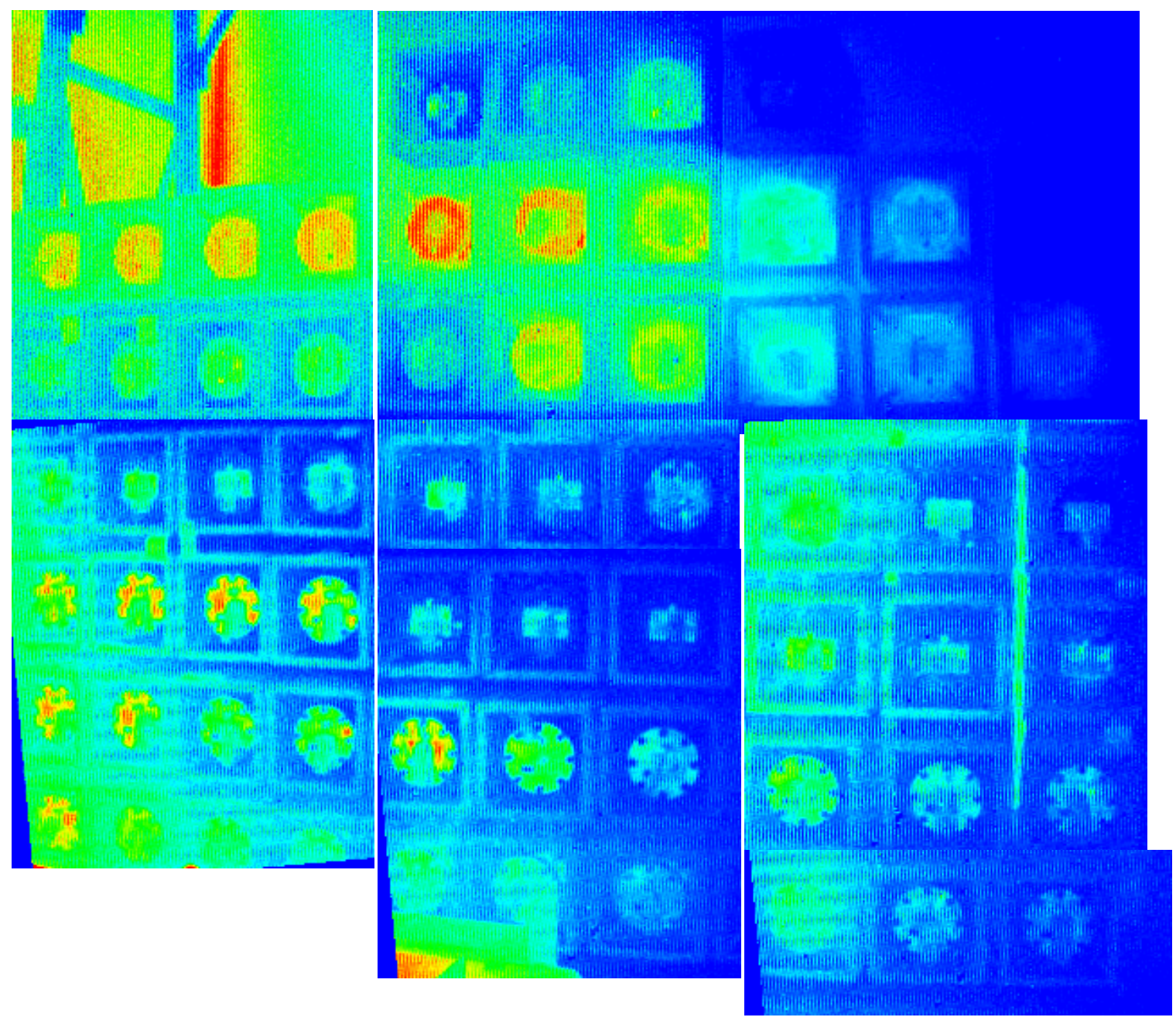

Figure 2. Model 60 Containers - July 30, 2003 (Temperature Range $77-80^{\circ} \mathrm{F}$, dark blue to bright red) 

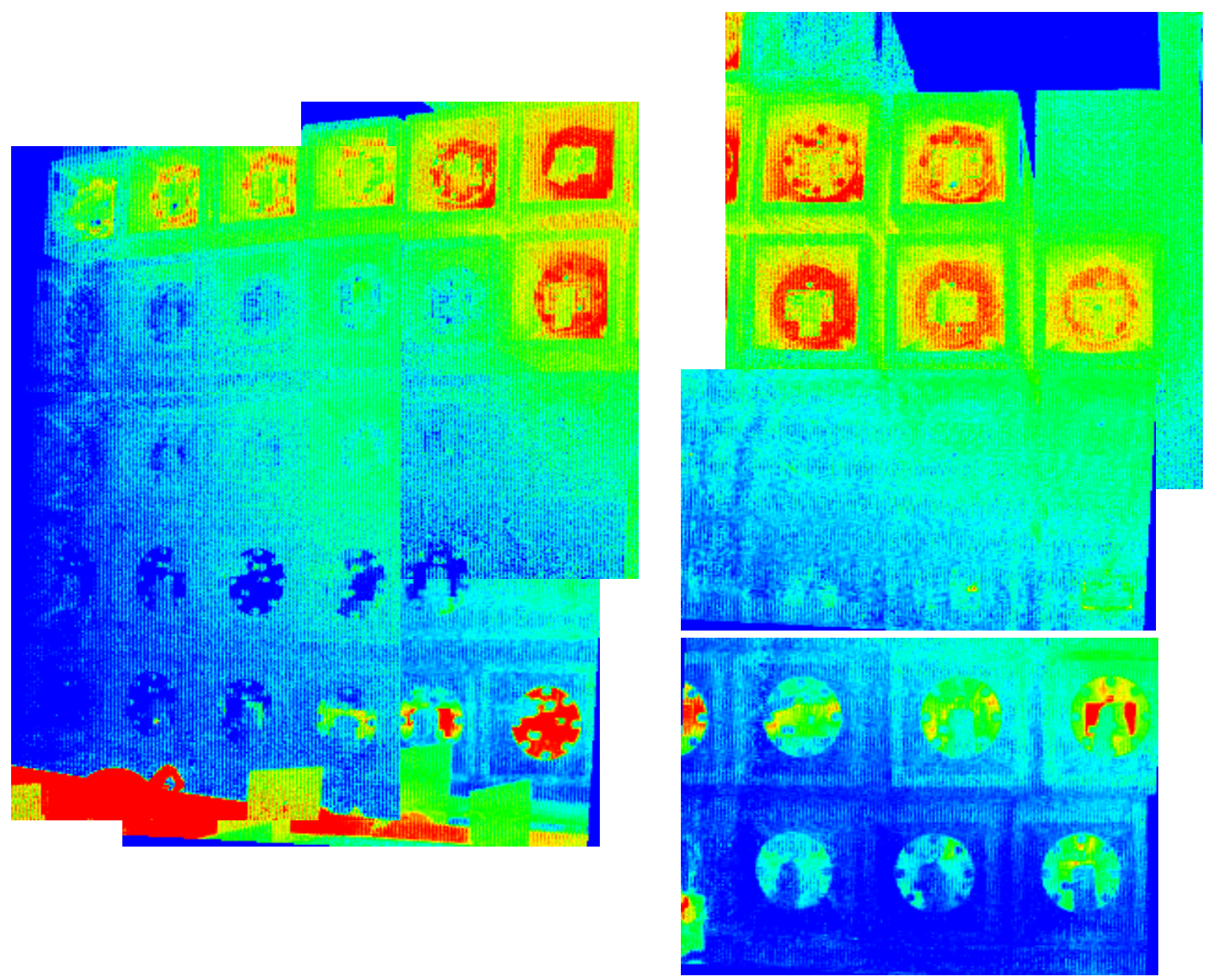

Figure 3. Model 60 Containers - December 30, 2003 (temperature range 65-68 ${ }^{\circ} \mathrm{F}$, dark blue to bright red) 


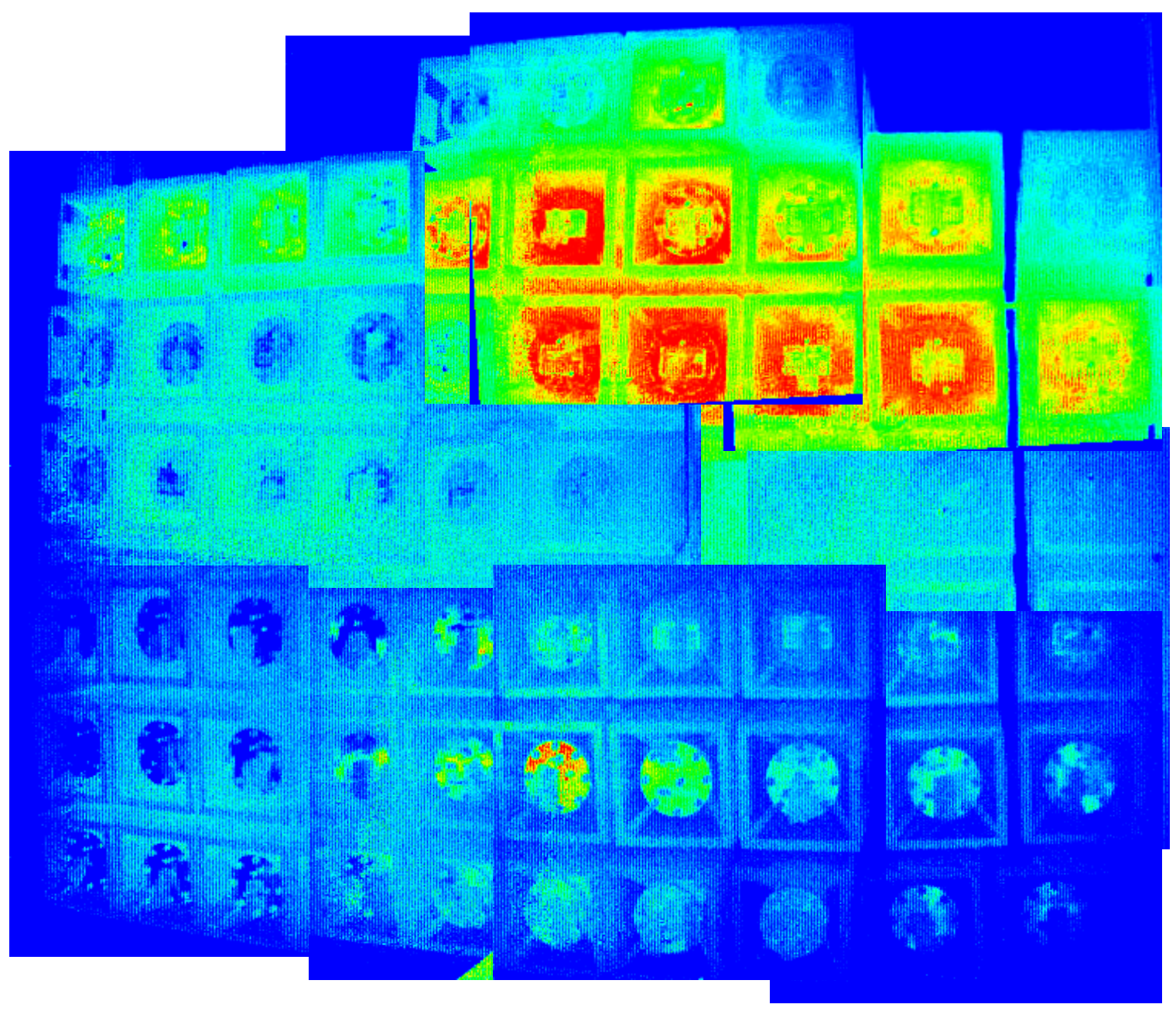

Figure 4. Model 60 Containers- January 28, 2003 (temperature range: $72-75^{\circ} \mathrm{F}$, dark blue to bright red) 

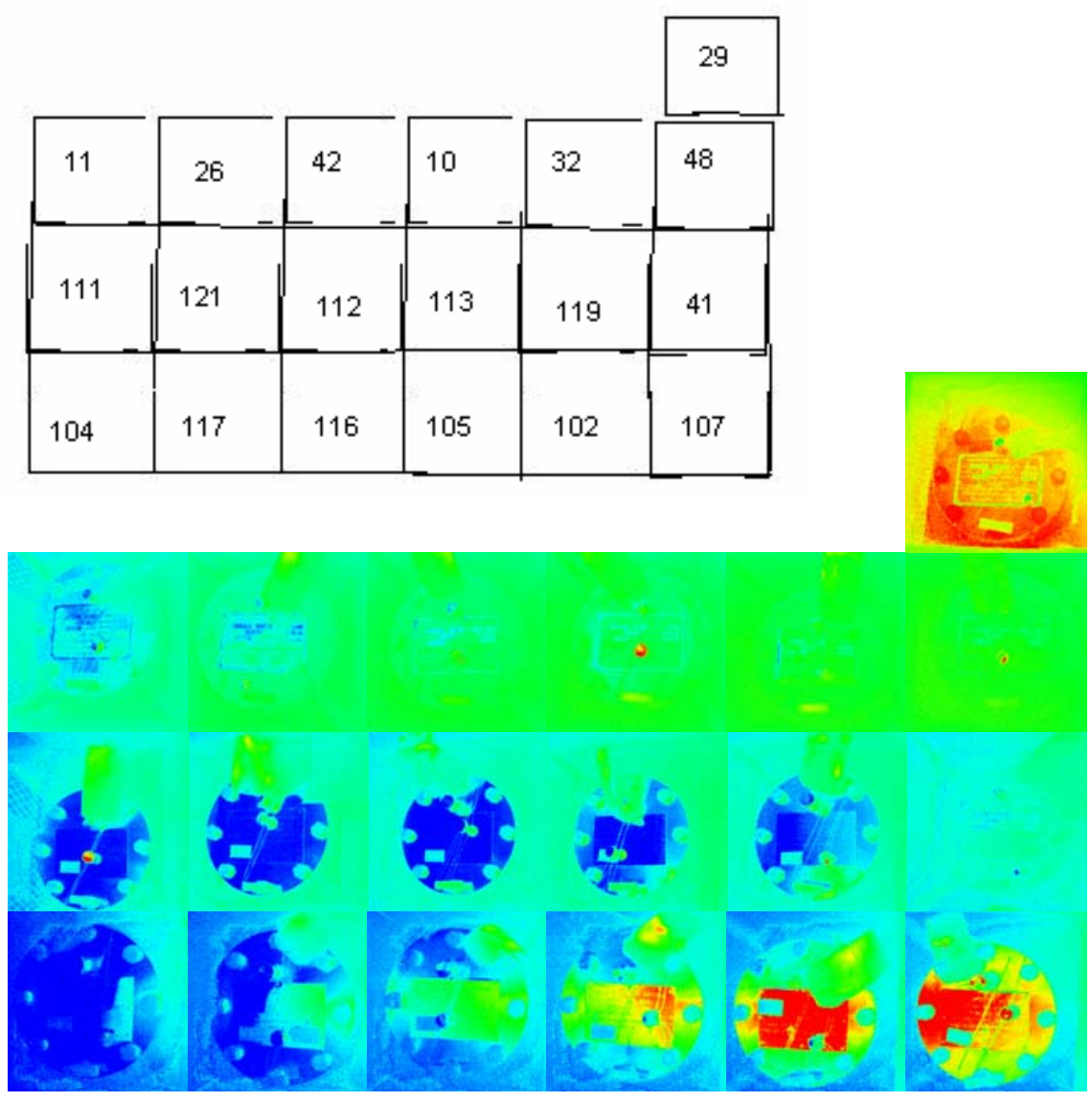

Figure 5. Close-Up of Some of the Model 60's Containers (temperature range: $70-75^{\circ} \mathrm{F}$, dark blue to bright red) 


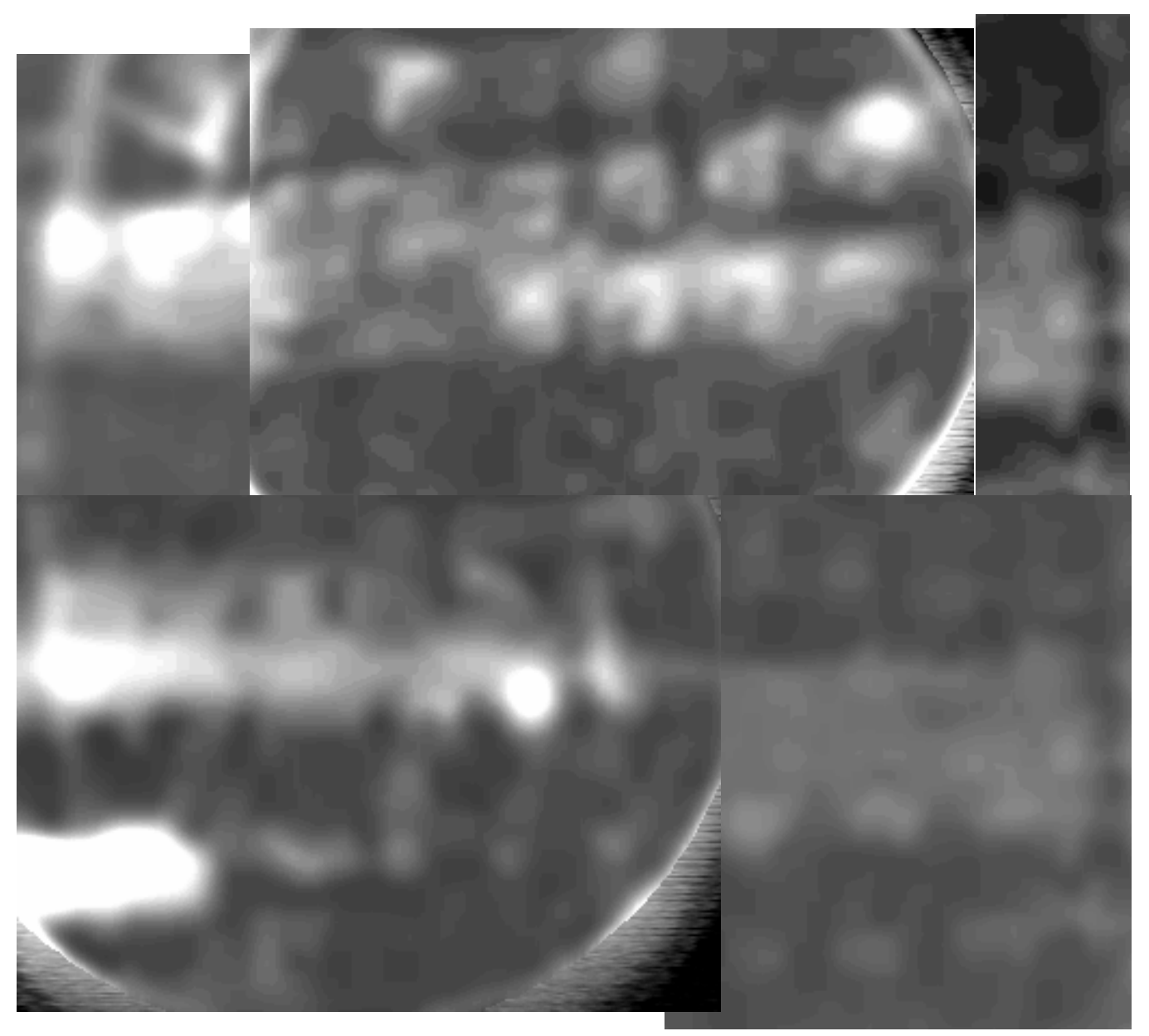

Figure 6. Enhanced Black and White Image with VideoTherm Camera 


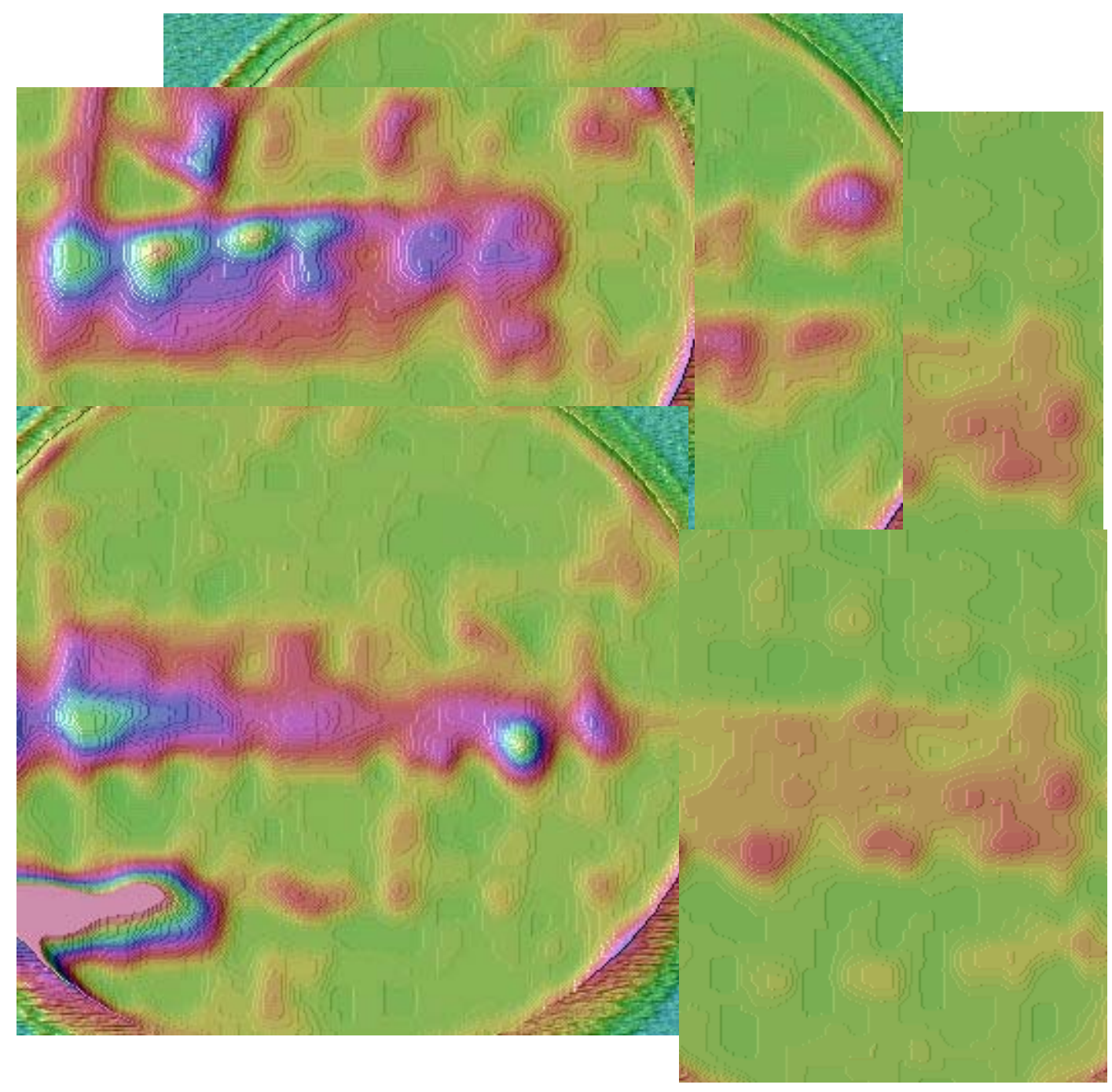

Figure 7. Model 60 PseudoColored Image from VideoTherm 
Table 1. Comparison of Three Tests with the IRRIS Infrared Camera (end caps that indicated warmth remaining end caps consistently did not indicate warmth)

\begin{tabular}{|c|c|c|c|c|c|c|c|}
\hline \begin{tabular}{|c|} 
Container \\
$\#$
\end{tabular} & $\begin{array}{c}\text { IRRIS } \\
(7 / 30 / 2003)\end{array}$ & $\begin{array}{c}\text { IRRIS } \\
(12 / 30 / 2003)\end{array}$ & \begin{tabular}{|c|} 
IRRIS \\
$(1 / 28 / 2004)$ \\
\end{tabular} & $\begin{array}{c}\text { Container } \\
\#\end{array}$ & $\begin{array}{c}\text { IRRIS } \\
(7 / 30 / 2003) \\
\end{array}$ & $\begin{array}{c}\text { IRRIS } \\
(12 / 30 / 2003)\end{array}$ & $\begin{array}{c}\text { IRRIS } \\
(1 / 28 / 2004) \\
\end{array}$ \\
\hline & & & & 101 & & $\mathrm{X}$ & $\mathrm{X}$ \\
\hline 3 & & $\mathrm{X}$ & $\mathrm{X}$ & 102 & $\mathrm{X}$ & $\mathrm{X}$ & $\mathrm{X}$ \\
\hline 4 & & $\mathrm{X}$ & $\mathrm{X}$ & 103 & $\mathrm{X}$ & Missing & \\
\hline 5 & $X$ & & & 104 & $\mathrm{X}$ & & \\
\hline 6 & $X$ & $\mathrm{X}$ & $X$ & 105 & $X$ & $\mathrm{X}$ & $\mathrm{X}$ \\
\hline 12 & $\mathrm{X}$ & $\mathrm{X}$ & $\mathrm{X}$ & 106 & & $\mathrm{X}$ & \\
\hline 14 & $\mathrm{X}$ & $\mathrm{X}$ & $X$ & 107 & $\mathrm{X}$ & $\mathrm{X}$ & $\mathrm{X}$ \\
\hline 18 & $X$ & & & 108 & & $\mathrm{X}$ & \\
\hline 19 & $\mathrm{X}$ & $\mathrm{X}$ & $\mathrm{X}$ & 109 & $\mathrm{X}$ & $\mathrm{X}$ & $\mathrm{X}$ \\
\hline 20 & $\mathrm{X}$ & $\mathrm{X}$ & $X$ & 110 & $\mathrm{X}$ & & \\
\hline 21 & $\mathrm{X}$ & $\mathrm{X}$ & $\mathrm{X}$ & 111 & $\mathrm{X}$ & & \\
\hline 22 & $\mathrm{X}$ & $\mathrm{X}$ & $X$ & 112 & $X$ & & \\
\hline 24 & $X$ & $\mathrm{X}$ & $X$ & 113 & $X$ & & \\
\hline 27 & $X$ & $\mathrm{X}$ & $X$ & 116 & $X$ & & \\
\hline 28 & $\mathrm{X}$ & $\mathrm{X}$ & $\mathrm{X}$ & 117 & $X$ & & \\
\hline 29 & $\mathrm{X}$ & $\mathrm{X}$ & $\mathrm{X}$ & 118 & $\mathrm{X}$ & Missing & $\mathrm{X}$ \\
\hline 35 & $\mathrm{X}$ & & & 119 & & & $\mathrm{X}$ \\
\hline 36 & $\mathrm{X}$ & & & 120 & $\mathrm{X}$ & Missing & \\
\hline 37 & $\mathrm{X}$ & & & 121 & $X$ & & \\
\hline 39 & $\mathrm{X}$ & & & 122 & $\mathrm{X}$ & Missing & $\mathrm{X}$ \\
\hline 41 & & & $X$ & 123 & $\mathrm{X}$ & Missing & \\
\hline 43 & $X$ & $X$ & $X$ & 124 & $\mathrm{X}$ & & $X$ \\
\hline 50 & & $X$ & $X$ & 125 & $X$ & Missing & \\
\hline
\end{tabular}

Table 2. Comparison of Thermocouple Measurement to IR Image (ambient temperature $=67.2^{\circ} \mathrm{F}$ )

\begin{tabular}{||c|c|c|l||}
\hline Container \# & Temp on End Cap & Temp on Steel Frame & \multicolumn{1}{|c|}{ IR Imager indicates } \\
\hline 119 & $66.4^{\circ} \mathrm{F}$ & $66.5^{\circ} \mathrm{F}$ & $\begin{array}{l}\text { End cap is near the same } \\
\text { temperature as the surroundings }\end{array}$ \\
\hline 19 & $68.5^{\circ} \mathrm{F}$ & $67.1^{\circ} \mathrm{F}$ & $\begin{array}{l}\text { End cap is warmer than the } \\
\text { surroundings }\end{array}$ \\
\hline 8 & $66.9^{\circ} \mathrm{F}$ & $67.1^{\circ} \mathrm{F}$ & $\begin{array}{l}\text { End cap is near the same } \\
\text { temperature as the surroundings }\end{array}$ \\
\hline 22 & $69.0^{\circ} \mathrm{F}$ & $67.8^{\circ} \mathrm{F}$ & $\begin{array}{l}\text { End cap is warmer than the } \\
\text { surroundings }\end{array}$ \\
\hline
\end{tabular}




\section{Radio-Reflectors}

\section{IRRIS 256-ST Imager}

A composite of the infrared image of the radio-reflectors located on the floor in room 192A is shown in Figure 8. A hot area is seen under the wooden board lying on the containers. The temperature under the wood board ranges from $90^{\circ} \mathrm{F}$ to $92^{\circ} \mathrm{F}$, whereas further down the tube the temperature is $82^{\circ} \mathrm{F}$ to $84^{\circ} \mathrm{F}$. Either the fuel pins are located near the center of the container, or the wooden board is impeding the air currents from cooling the tube. The end caps are about $80^{\circ} \mathrm{F}$, whereas the background is about $78^{\circ} \mathrm{F}$.

The image in Figure 9 is the end cap of the container that was lying near the door and perpendicular to the other containers on the floor. It appears that there were no fuel pins in this container because the average temperature of the end cap is $80^{\circ} \mathrm{F}$, the same as the background temperature. An attempt was made to obtain an image of the middle of this container, but this was not possible due to the grating surrounding this storage container. In the December 2003 tests, a contact thermocouple was placed on the end cap of this radio-reflector, and it was determined that the end cap was measuring $68.2^{\circ} \mathrm{F}$, whereas the grating near the end was measuring $68.8^{\circ} \mathrm{F}$. Thus, an image could not be seen because the end cap, and the rest of the radio-reflector, are at the same temperature as the surroundings. The infrared image was consistent with the thermocouple readings.

\section{VideoTherm 94 Imager}

The VideoTherm camera was used to image the radio-reflectors on the floor in room 192A. The images are shown in Figure 10. When this test was done on July 30, 2003, a hot spot was noticed on each of the radio-reflectors near their center. A wooden board was lying across the center of the radioreflectors during these tests, and there was some debate as to whether the hot area under the board is due to the radiation sources or the blocking of air currents around the center of the radio-reflectors. For the tests on December 30, 2003, the wooden board was removed a day before the tests were conducted in order to equilibrate any heat build up due to the wooden board. From the image seen in Figure 10, one sees that the heat is still quite evident at the center, indicating that the heat is being generated by the stored fuel inside the radio-reflectors, which is near the center of the tubes. For these images, red indicates a warm area and blue indicates a cool area. The sidebar in the VideoTherm image indicated an ambient temperature of about $66^{\circ} \mathrm{F}$, and $78^{\circ} \mathrm{F}$ in the hot area. With a contact thermocouple on reflector \#5 (fifth one from the doorway), ambient temperature was measured at $67.2^{\circ} \mathrm{F}$, whereas a temperature of $68.7^{\circ} \mathrm{F}$ was measured in an area not in the middle of the reflector, and $76.7^{\circ} \mathrm{F}$ in the middle of reflector \#5. 


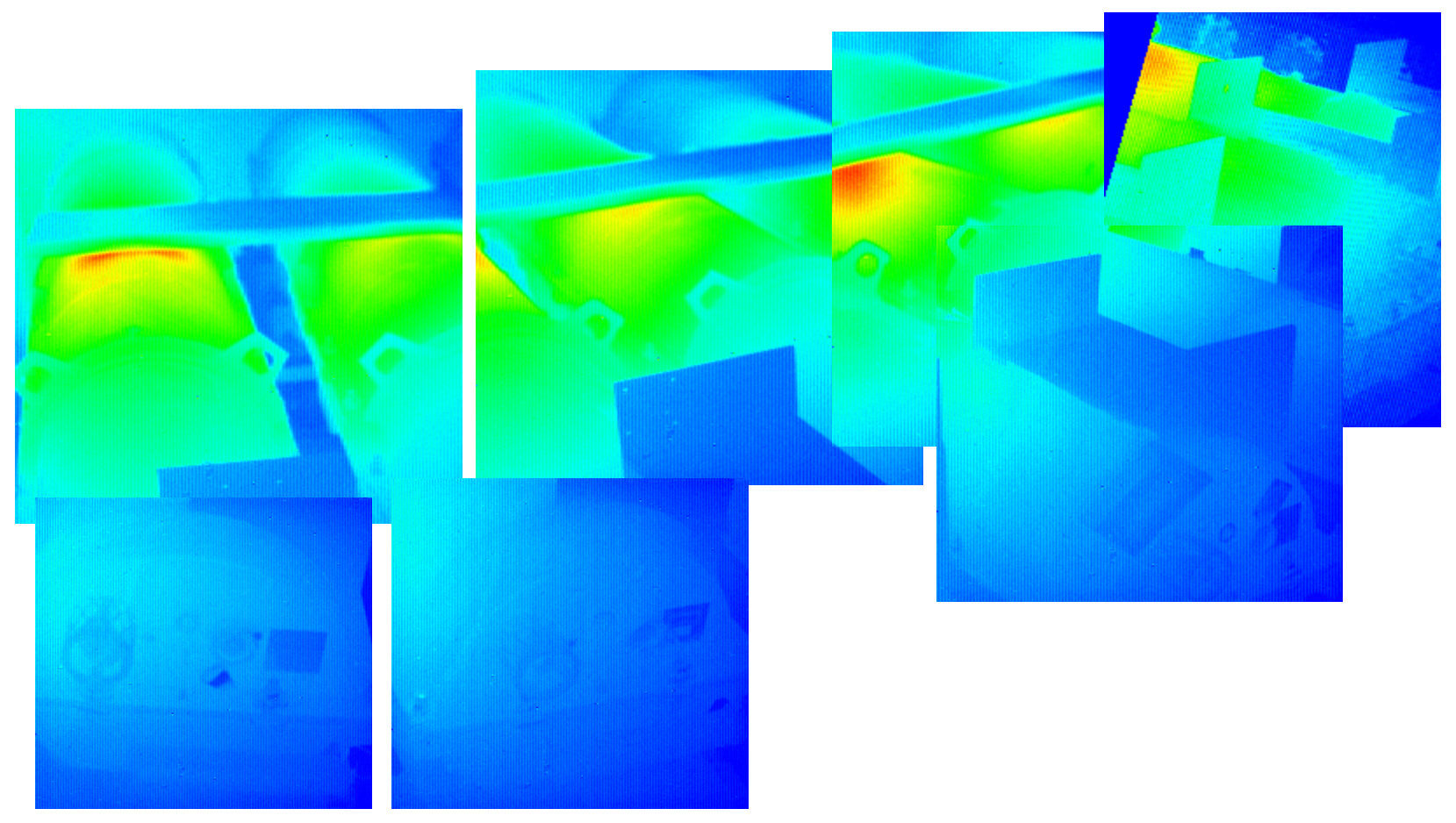

Figure 8. Radio-Reflectors (delta temperature $79-93^{\circ} \mathrm{F}$, dark blue to bright red)

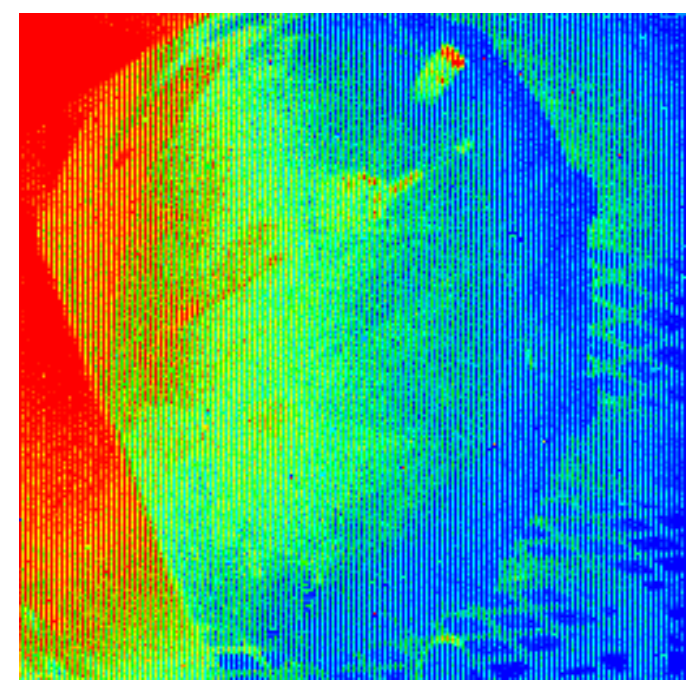

Figure 9. Infrared Image of Retro-Reflector Near Door Perpendicular to Other Tubes (delta temperature $79^{\circ} \mathrm{F}$ to $82^{\circ} \mathrm{F}$, dark blue to bright red) 


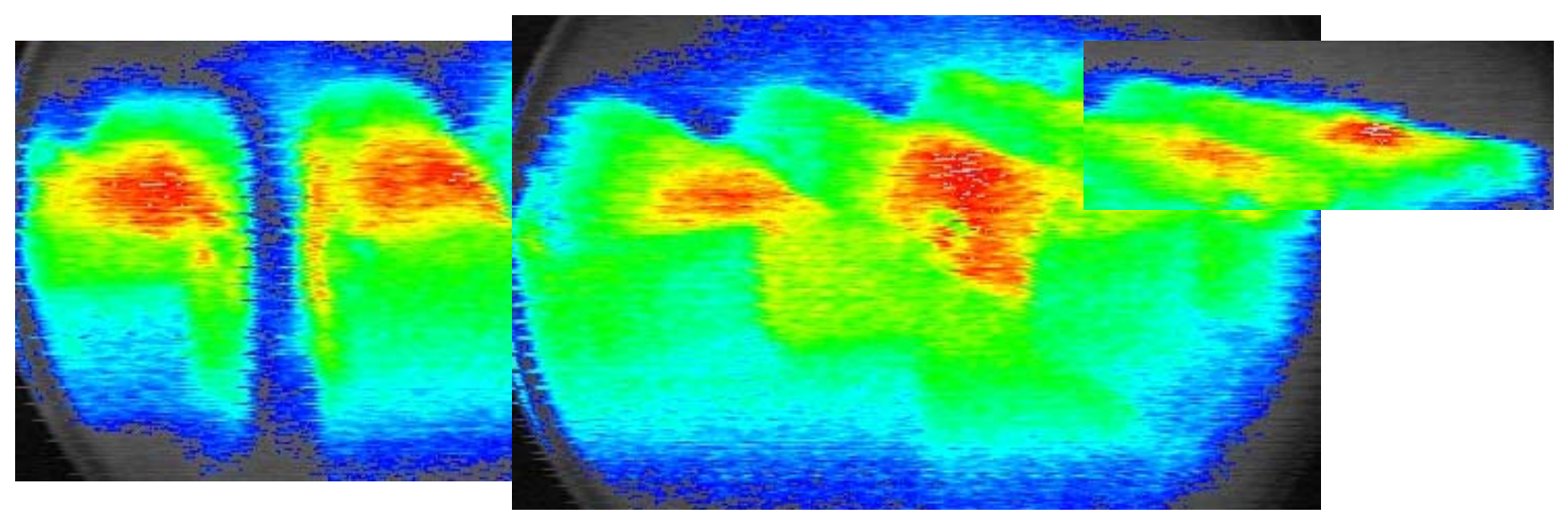

Figure 10. Radio-Reflectors

\section{Containers}

Several 3013 containers of radioactive material were examined with the VideoTherm camera. A single container sitting on the bench is shown in Figure 11, and several containers sitting in a transport wagon are shown in Figure 12. With the contact thermocouple, the ambient temperature was measured to be $67.8^{\circ} \mathrm{F}$ and the temperature of the single can was $98.4^{\circ} \mathrm{F}$. Because the can is stainless steel, it has a low emissivity (a measure of an object's ability to radiate energy), which resulted in the camera measuring the can temperature in the range of $74-77^{\circ} \mathrm{F}$, with an ambient temperature of $69^{\circ} \mathrm{F}$. The infrared image is a function of not only the temperature of the object, but also its emissivity. An emissivity of unity is assumed in the camera measurements.

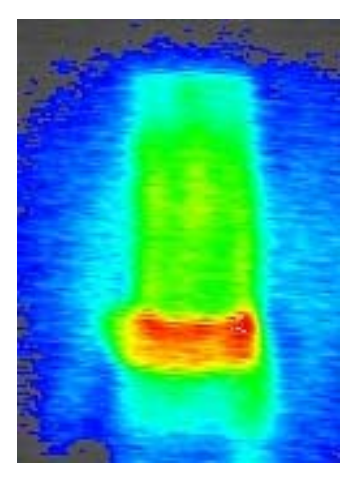

Figure 11. Single 3013 Container on Bench 


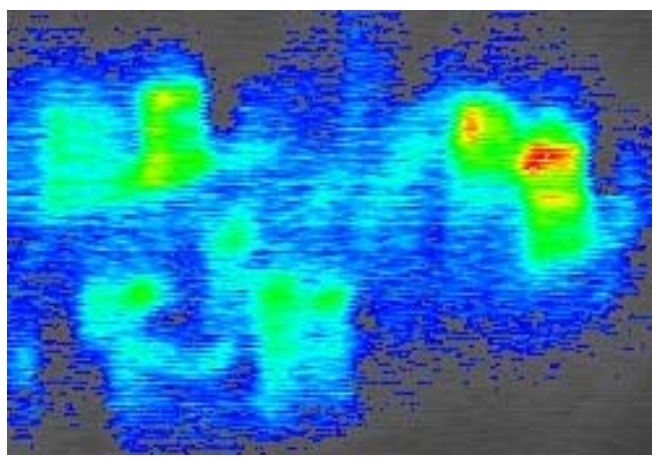

Figure 12a. 3013 Containers in Transport Wagon

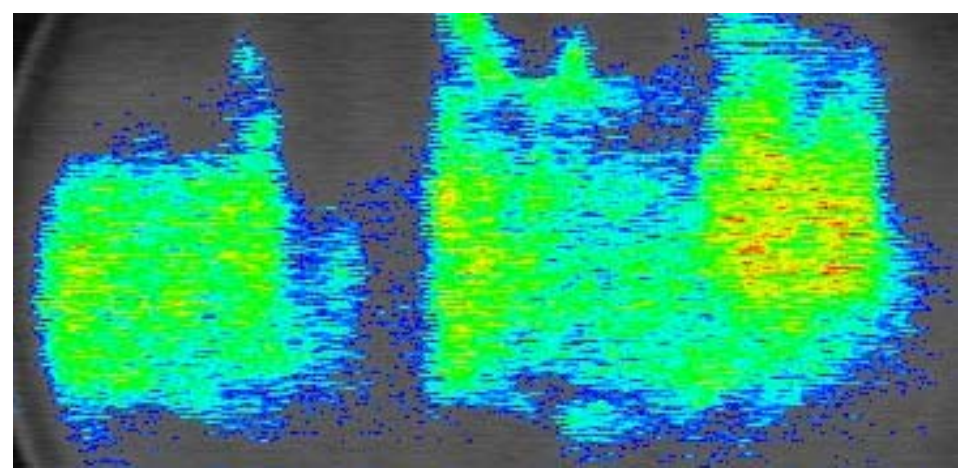

Figure 12b. Close up of 3013 Containers in Wagon

Figure 12. Infrared Images of 3013 Containers in Transport Wagon

\section{Vault}

The VideoTherm was taken into a vault to measure the temperature of the end of the stored containers. However, this area required Rad Worker II training, and the PNNL operator of this equipment did not have this level of training. So a Fluor Hanford employee tried to take these measurements, but did not have the camera set properly and no definitive images were obtained. The best image that could be obtained from the video tape is shown in Figure 13. However, the temperature readings on the VideoTherm sidebars indicated the camera was seeing a temperature range from $68^{\circ} \mathrm{F}$ to $79^{\circ} \mathrm{F}$. So with the proper settings on the instrument, an image should be obtained. 


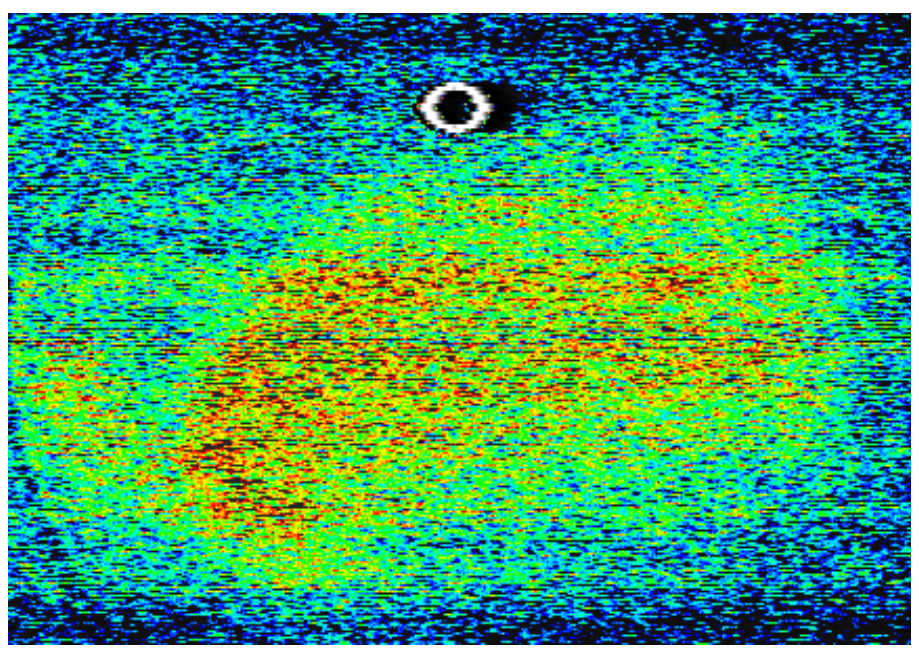

Figure 13. Image Inside Vault

\section{Conclusions}

Infrared imaging can be used to detect the presence of fuel rods in storage containers. However, the temperature difference between the end plates and the ambient temperature is not great (generally about $1^{\circ} \mathrm{F}$ ), and can be overshadowed by reflections, change in emissivity of the surface, etc. Table 1 shows there is some consistency between the three test series, and the infrared image was consistent with all of the contact thermocouple measurements taking during these test series. Some of the end plates were much hotter than others, probably due to the amount, type, and location of the material stored in them and any packing material also stored in the containers. The material stored in the Radio-Reflectors shows that the material is stored in the middle of the containers and is much warmer than the surrounding or what is seen at the end plate. A high-quality imager produced much better results than the lower quality imager because of the small temperature differences being observed. The images from the infrared cameras were consistent with thermocouple measurements. The main advantage of using the infrared imager is that a larger area of storage containers can be measured more quickly than with a contact thermocouple probe and without the need to get up close to the containers, exposing personnel to radiation. The infrared image of the 64 containers taken from a distance was obtained in about ten minutes. A scan of the storage containers could be performed even more quickly with a larger field-of-view (FOV) imaging lens for the infrared imagers, but the 25-mm focal length lens was the largest FOV lens that PNNL presently has for these imagers. Infrared lenses are expensive (\$8000-\$10,000), but it would save time in taking the data and processing the image if all, or most, of the containers could be observed in one image, rather than obtaining a single image from piecing together a series of images. Testing indicated that moving closer to the containers did not help the resolution and resulted in a lost of the advantages of the technique (taking data quickly and from far away). 


\section{Recommendations}

Infrared imaging should continue to be explored as a possible method to determine the contents of the storage containers. Generally, the data taken at different times of the year was consistent, but there were some inconsistencies that need to be explored. Various techniques were tried during these tests, which could explain some of the inconsistencies. The advantage of quickly determining that there is material in the storage containers from a distance makes infrared imaging a viable method for surveying any changes in the container contents. 


\section{Distribution}

No. of

Copies

ONSITE

3 Fluor Hanford

GB Hulse (3)
No. of

Copies

12 Pacific Northwest National Laboratory

TJ Peters (5)

K5-17

Information Release (7)

T5-50 